\title{
Hidden sources of fluid and sodium intake in ill newborns
}

\author{
C M NOBLE-JAMIESON, P KUZMIN, AND K I AIREDE
}

Department of Paediatrics and Neonatal Medicine, Royal Postgraduate Medical School, Hammersmith Hospital, and Department of Paediatrics, Charing Cross Hospital Medical School, London

SUMMARY Fluids used for flushing arterial catheters, bronchial lavage, and drug administration are not normally considered when assessing daily fluid intake, yet infants weighing less than $1000 \mathrm{~g}$ at birth gained up to $12 \mathrm{ml} / \mathrm{kg} /$ day of extra fluid and 2.4 $\mathrm{mmol} / \mathrm{kg} /$ day (mean) of extra sodium from these hidden sources.

Fluid and electrolyte balance is an important part of neonatal intensive care, ${ }^{1}$ and the sequelae of dehydration and fluid overload are well known. ${ }^{2}{ }^{3}$ The volume of fluid used to flush catheters, administer drugs to the baby, and carry out bronchial lavage are, however, traditionally ignored. We have assessed the contribution of these hidden sources to fluid and sodium intake in infants requiring intensive care.

\section{Patients and methods}

We studied 19 infants undergoing intensive care during the first five days of life. All were mechanically ventilated and had arterial catheters inserted within a few hours of birth. All but one infant required intravenous treatment with drugs. At birth eight of the infants weighed less than $1000 \mathrm{~g}$, six weighed $1000-1500 \mathrm{~g}$, and five weighed over $1500 \mathrm{~g}$.

We recorded the prescribed amount of fluid and sodium and also the extra fluid and sodium gained by the baby from sources that are not normally recorded. The prescribed volume of fluid was frequently reassessed according to the infants' needs as judged by weight change, plasma sodium concentration, urine specific gravity, and the pres- ence of patent ductus arteriosus. In the first three days of life dextrose was used; thereafter most babies progressed to parenteral nutrition. Plasma was given when required.

The extra fluid gained through the flushing of arterial catheters was taken as the amount of saline administered in excess of the volume required to replace the blood sampled. All babies had bronchial lavage from about the third day of life: we studied the amount of saline remaining in the baby after lavage and calculated the net fluid and sodium intake from this source. When an intravenous drug was administered $0.5 \mathrm{ml}$ of saline was used in flushing the intravenous line. This was included in calculations of the extra fluid and sodium gained during drug administration.

\section{Results}

The extra fluid and sodium gains from the three 'hidden' sources are given in the Table. Infants weighing less than $1000 \mathrm{~g}$ at birth gained the largest amount of fluid and sodium (up to 12.3 (SD 6.0) $\mathrm{ml} / \mathrm{kg} /$ day of extra fluid and up to 2.4 (SD 1.2) $\mathrm{mmol} / \mathrm{kg} /$ day of extra sodium on the third day of life). Larger infants gained relatively less fluid and sodium. Two infants weighing $720 \mathrm{~g}$ and $820 \mathrm{~g}$ became hypernatraemic (plasma sodium concentrations 165 and $156 \mathrm{mmol} / \mathrm{l}$, respectively) despite high fluid intakes. In the remaining infants the plasma sodium concentrations remained within the range 131-149 $\mathrm{mmol} / \mathrm{l}$ throughout the study.

Infants gained fluid during each bronchial lavage. We found that over $70 \%$ of the saline used in lavage remained in the baby. The calculated daily intake from this source is given in the Table. Drug

Table Contribution to extra fluid ( $\mathrm{ml} / \mathrm{kg} /$ day) and sodium ( $\mathrm{mm}$ ol $/ \mathrm{kg} /$ day) intake during the first five days of life from flushing of arterial catheters, bronchial lavage, and drug administration. Values are mean (SD)

\begin{tabular}{|c|c|c|c|c|c|c|c|c|}
\hline \multirow[t]{2}{*}{ Birth weight $(g)$} & \multicolumn{2}{|c|}{ Arterial flush } & \multicolumn{2}{|c|}{ Bronchial lavage } & \multicolumn{2}{|c|}{ Drug administration } & \multicolumn{2}{|l|}{ Total } \\
\hline & Volume & Sodium & Volume & Sodium & Volume & Sodium & Volume & Sodium \\
\hline$<1000$ & $2.7(1.9)$ & $0.49(0.39)$ & $3.0(1.4)$ & $0.46(0.21)$ & $4.4(2.6)$ & $0.68(0.61)$ & $10 \cdot 1(4 \cdot 5)$ & $1.6(0.8)$ \\
\hline $1000-1500$ & $1.6(0.6)$ & $0.24(0.09)$ & $2 \cdot 1(1 \cdot 3)$ & $0.31(0.19)$ & $3.4(2.4)$ & $0.38(0.30)$ & $7 \cdot 1(2 \cdot 5)$ & $0.9(0.4)$ \\
\hline$>1500$ & $1.0(0.7)$ & $0 \cdot 15(0 \cdot 10)$ & $1.1(0.8)$ & $0.17(0.12)$ & $2.2(1.7)$ & $0.50(0.61)$ & $4 \cdot 3(2 \cdot 2)$ & $0.8(0.8)$ \\
\hline
\end{tabular}


administration was the largest source of extra fluid and sodium, with a mean (SD) contribution of 4.4 $(2 \cdot 6) \mathrm{ml} / \mathrm{kg} /$ day of fluid and $0 \cdot 68(0 \cdot 61) \mathrm{mmol} / \mathrm{kg} /$ day of sodium during the five day period in infants weighing less than $1000 \mathrm{~g}$ at birth.

The absolute amount of fluid and sodium gained from the three hidden sources was similar in all infants regardless of body weight, but when normalised for body weight the contribution from the three hidden sources was less significant in larger infants.

\section{Discussion}

Newborns undergoing intensive care gain significant amounts of fluid and sodium from drugs, bronchial lavage, and flushing of catheters-sources that are not normally taken into account when calculating the daily requirement. The proportion of extra fluid gained depends very much on the weight of the infant, peaking at a mean of $12 \mathrm{ml} / \mathrm{kg} /$ day in infants aged 3 days weighing less than $1000 \mathrm{~g}$ at birth. The amount of extra fluid gained in larger infants was probably not clinically significant in our study group but might have been significant in an infant in severe renal failure. The largest source of 'hidden' fluid was drugs, and this should lead to a reappraisal of the dilutions used, and in particular of whether it is necessary to flush the intravenous catheter before and after injecting each drug. Similarly, to flush an arterial catheter it should not be necessary to do more than replace the volume of blood sampled.

We were surprised at how much extra sodium could be gained from these 'hidden' sources. It was not our normal policy to prescribe sodium in the first two to three days of life, yet the mean gain in sodium from these sources in the first five days of life was $1.6 \mathrm{mmol} / \mathrm{kg} /$ day in the infants weighing less than $1000 \mathrm{~g}$ at birth. The largest source for 'hidden' sodium was the administration of drugs. Once again it was the saline used in flushing the intravenous line before and after the administration of each drug that contributed most.

A significant proportion of the fluid and sodium intake of infants in intensive care comes from sources that are not normally recorded. Frequent reappraisal of the fluid requirements will tend to minimise the clinical significance of the 'hidden' fluid intake, except in infants with severe renal failure. The sodium load from these hidden sources, however, may be much more important, as excessive intake might not be obvious clinically but could result in fluid retention. Clinicians involved in neonatal intensive care should be aware of these hidden sources of sodium and fluid, as they can readily be eliminated by simple changes in unit policy.

We thank Dr J Jethusathan, Dr J Dave, and the nursing staff of Hammersmith Hospital and the West London Hospital neonatal units for their help with this project.

\section{References \\ I Lorenz JM, Kleinmann LI. Kotagal UR. Reller MD. Water balance in very low birth weight infants: relationship to water and sodium intake and effect on outcome. $J$ Pediatr 1982;101:423-32 \\ 2 Brown ER, Stark A. Sosenko I, Lawson EE, Avery ME. Bronchopulmonary dysplasia: possible relationship to pulmon- ary edema. J Pediatr 1978:92:982-4 \\ 3 Bell EF, Warburton D. Stonestreet BS, Oh W. Effects of fluid administration on the development of symptomatic patent ductus arteriosus and congestive heart failure in premature infants. $N$ Engl J Med 1980;302:598-604.}

Correspondence to Dr C M Noble-Jamieson, 24 Priory Terrace, London NW6 4DH, England.

Received 12 March 1986

\title{
High plasma urea concentrations in collodion babies
}

\author{
D W BEVERLEY AND D WHEELER
}

Bradford Children's Hospital, Bradford, and St James's University Hospital, Leeds

\begin{abstract}
SUMMARY We describe two infants born with a collodion membrane; both were treated with a product containing $10 \%$ urea and $5 \%$ lactic acid and as a consequence were found to have a raised plasma urea concentration.
\end{abstract}

Therapeutic and toxic transdermal absorption of drugs is now well documented. ${ }^{1-6}$ We describe two infants with collodion baby syndrome who developed a high plasma urea concentration during treatment with Calmurid (10\% urea, $5 \%$ lactic acid) when it was used as a skin hydration and keratolytic agent. 